\title{
Sensory inputs to the nucleus basalis prosencephali, a feeding-pecking centre in the pigeon
}

\author{
Ulrich Schall and Juan D. Delius \\ Experimentelle Tierpsychologie, Psychologisches Institut, Ruhr-Universität Bochum, D-4630 Bochum, \\ Federal Republic of Germany
}

\begin{abstract}
Summary. Evoked potentials were recorded from the nucleus basalis prosencephali (Bas) of the pigeon through chronically implanted electrodes. The auditory sensitivity of the Bas was assessed by the amplitude of the potentials. Audiograms thus obtained were comparable to those similarly measured from stations of the orthodox auditory pathway and resembled those obtained by others with behavioural techniques from the same species. The sensitivity to vibration applied to the beak was also measured. The vibrogram revealed two separate optima, one located in the lower frequency and another in the higher frequency region. These were shown to be due to trigeminal mechanoreceptive sensitivity and to bone/cochlea mediated sound sensitivity, respectively. Evoked potentials of the Bas in response to vestibular stimulation are described for the first time. The possibility that they were artefacts was excluded with several control procedures. These findings confirm recent anatomical evidence of a direct pathway from the vestibular nucleus to the nucleus basalis prosencephali. All afferents to the Bas are discussed in conjunction with the probable function of the nucleus as a sensorimotor coordinator of the pigeon's pecking/feeding behaviour.
\end{abstract}

\footnotetext{
Abbreviations: A archistriatum; $a L$ area $\mathrm{L}$ of the medial neostriatum caudale; Bas nucleus basalis prosencephali; $C b$ cerebellum; $F A$ tractus fronto-archistriatalis; $H A$ hyperstriatum accessorium; $H p$ hippocampus; $H R P$ horseradish peroxidase; $H V$ hyperstriatum ventrale; $L L v$ nucleus lemnisci lateralis, pars ventralis; $L P O$ lobus parolfactorius; $M V$ nucleus motorius nervi trigemini; $M L d$ nucleus mesencephalicus lateralis, pars dorsalis; $n V I$ nucleus nervi facialis; $n V I I I$ nervus vestibulocochlearis; $N$ neostriatum; $N F L$ neostriatum frontolaterale; $O M$ tractus occipitomesencephalicus; $O v$ nucleus ovoidalis; $\operatorname{Pr} V$ nucleus sensorius principalis nervi trigemini; $Q F$ tractus quintofrontalis; $R p v$ nucleus reticularis parvocellularis, pars lateralis; TrO tractus opticus; $V S$ nucleus vestibularis superior
}

\section{Introduction}

Brain lesion (Zeigler 1976), electrical stimulation (Delius 1971) and, more recently, chemical stimulation (Delius 1985; Lindenblatt, in prep.) and metabolic labelling studies (Delius 1985; Delius and Scheich, in prep.) suggest that the nucleus basalis prosencephali (Bas), a peculiarity of birds that has no known homologue or analogue in mammals, is involved in the motor control of feeding or more precisely in the control of pecking, grasping and swallowing. The neostriatum frontolaterale (NFL) in the immediate neighbourhood of the Bas, and with which it is intimately connected, projects via the tractus fronto-archistriatalis (FA) to the anterior archistriatum (A) (Wild et al. 1984; Schall et al. 1986). The archistriatum in turn projects via the tractus occipitomesencephalicus (OM) to a variety of di-, mes-, rhombencephalic and spinal structures (Zecha 1962; Zeier and Karten 1971; Berkhoudt et al. 1982). Berkhoudt et al. (1982) established that a mesencephalic target of the OM, the nucleus reticularis parvocellularis, pars lateralis (Rpv) projects to the nucleus motorius nervi trigemini (MV) and nucleus nervi facialis (nVI). These latter nuclei in turn innervate the beak musculature (Wild and Zeigler 1980).

As to sensory afferents to the Bas, the subject of the present paper, Wallenberg already discovered in 1903 that it receives a direct bilateral projection from the nucleus sensorius principalis trigemini (PrV) in the tractus quintofrontalis (QF), bypassing the thalamus (see also Wallenberg 1966; Dubbeldam et al. 1981; Wild et al. 1984). Electrophysiological work (Witkovsky et al. 1973; Berkhoudt et al. 1981) has since shown that the Bas responds with a remarkably short latency (4-8 ms) to electrical and tactile stimulation of the orobuccal lining. A precise specification of the effective 
physical characteristics of the mechanical stimuli capable of activating the Bas is still lacking, however.

Both a decussating and non-decussating projection from the nucleus lemniscus lateralis, pars ventralis (LLv), mentioned by Kirsch (1983) for the starling (Sturnus vulgaris), was recently confirmed for the pigeon (Columba livia) on the basis of retrograde horseradish peroxidase (HRP) transport after injection into the Bas (Schall et al. 1986). The $\mathrm{LLv}$ is known to receive direct input from the nucleus angularis, pars medialis and the nucleus magnocellularis, pars medialis, rhombencephalic terminations of the cochlear component of the eighth nerve (nVIII) (Boord 1968; Correia et al. 1982). Much earlier, Iljitschew and coworkers (Naumov and Iljitschew 1964; see also Harman and Phillips 1967) had recorded short latency (5-8 ms) auditory evoked potentials from the Bas area. Although they were initially disregarded by others as artefacts (Karten 1969) they are genuine cochlearly driven responses (Delius et al. 1979; see also Berkhoudt et al. 1981; Kirsch 1983). It is not known, however, whether the responses of the Bas show a specialized frequency sensitivity as compared to the orthodox auditory pathway to the telencephalon. This pathway has stations in the mesencephalon (nucleus mesencephalicus lateralis, pars dorsalis (MLd), homologous to the colliculus inferior of mammals) and in the thalamus (nucleus ovoidalis $(\mathrm{Ov})$, homologous to the nucleus geniculatus medialis of mammals) and terminating in the medial neostriatum caudale, the area L (homologous to the auditory cortex in mammals).

Schall et al. (1986) discovered that the Bas of the pigeon receives further afferents from sensory structures that had not been reported previously. Most striking was a direct crossed projection from the nucleus vestibularis superior (VS). The VS, a rhombencephalic termination of the vestibular component of the nVIII appears to receive input mainly from the ipsilateral ampullary receptors (Wilson and Felpel 1972; Wold 1975). Nothing is known about a physiological responsiveness of the Bas to vestibular stimulation that might relate to this vestibulofugal pathway.

The Bas also receives, as Schall et al. (1986) showed, afferents from the peri-ectostriatal belt, a visual projection area (Karten and Hodos 1970; Parker and Delius 1972; Ritchie and Cohen 1977) and from the tuberculum olfactorium, an olfactory projection area (Rieke and Wenzel 1978; Macdar et al. 1980) but these afferents will not concern us here. The present paper's aim is to extend the knowledge concerning the characteristics of the au- ditory and vibratory sensitivity of the Bas and to establish that it also responds with short latencies to vestibular stimulation.

\section{Materials and methods}

13 adult pigeons (Columba livia) of local stock were used. All surgery was performed under general pentobarbital/chloral hydrate anaesthesia (see Mallin and Delius 1983 for details) and, where relevant, under additional topical xylocaine anaes. thesia. Any bleeding was controlled with thrombin and wounds were treated with sulfonamide. The animals were postoperatively injected with an antibiotic.

Recording electrodes were implanted stereotactically (Karten and Hodos 1967) into the Bas and either into the area L (aL) of the medial neostriatum caudale, or the nucleus mesencephalicus lateralis, pars dorsalis (MLd) of all birds. The position of the electrodes during implantation was additionally checked by recording evoked responses to auditory stimuli delivered with a miniature loudspeaker coupled to the hollow ear-bars of the stereotactic instrument. The electrodes consisted of a pair of insulated stainless steel wires $(0.01 \mathrm{~mm}$ diam.) with bare tips $(0.5 \mathrm{~mm})$ staggered $1 \mathrm{~mm}$ apart. A loop of bare stainless steel wire placed under the scalp served as an indifferent electrode. All the electrodes terminated in a miniature connector that was cemented to the skull.

In 3 animals the canalis semicircularis posterior (sagittal semicircular canal) contralateral to the Bas electrode was exposed through an opening of the occipital surface of the skull, some $4 \mathrm{~mm}$ lateral from the occiput just ventral to the insertion of the neck muscles. At this location the canalis semicircularis posterior crosses over the canalis semicircularis externus (horizontal canal). This landmark is faintly visible through the skull surface due to a sinus venosus that accompanies the canals. The posterior bony canal was exposed for about $1.5 \mathrm{~mm}$ above and below the crossing and two small perforations were made into it. Two insulated stainless steel wires $(0.1 \mathrm{~mm}$ diam. $)$, with the ends exposed for $1.5 \mathrm{~mm}$ and tightly bent over to form blunt tips, were carefully inserted through these openings for about $1.5 \mathrm{~mm}$ towards the canal's ampulla, without damaging the membranous canal. They were fixed with surgical glue to the bone casing and led to a connector cemented to the skull. The skin was sutured over the wound around the connector.

The ipsilateral cochlea was removed from one of the above animals and bilaterally removed from 5 other birds following a procedure similar to that described by Schwartzkopff (1949). Starting from the ventro-lateral quadrant delimited by the sagittal and horizontal canals, which where exposed as described above, bone trabecula were removed in a beakward direction until the ampulla of the posterior canal could be seen with the aid of an operating microscope. About $0.25 \mathrm{~mm}$ medially and ventrally from the ampulla the bony inner ear casing was opened at the base of the cochlea. A fine wire hook was introduced through this perforation for about $3 \mathrm{~mm}$ in a beakward direction and then retracted, thus pulling out the membranous cochlea including the lagena. The opening was closed with a drop of surgical cement. The hollow in the skull bone was filled with surgical gelatine sponge and the skin sutured.

The trigeminal nerve branches that innervate the face and the beak were bilaterally transsected in two birds according to a technique similar to that of Zeigler et al. (1975). For this the skin and connective tissue between the ventro-posterior edge of the eye and the external auditory meatus was incised to give access to the orbital cavity. The eye was slightly compressed in a dorso-frontal direction with a specially made minia- 
ture wound retractor. With the aid of an operating microscope the ophthalmic, maxillary and mandibular branches of the trigeminal nerve were lifted onto a wire hook and cut with iridectomy scissors. The skin was sutured over the wound. In two other birds a reversible blockade of the same trigeminal branches was brought about by multiple injections of a total of $0.5 \mathrm{ml}$ of xylocaine and novocaine solution at the site where the nerve branches enter the orbital cavity. In another bird a blockade was produced with similar injections into the soft palate of the beak. The effectiveness and temporal course of these blockades was gauged by observing the Bas potentials evoked by electrical stimulation of the soft palate.

All recording was made from awake birds several days after the electrode implantation and again after recovery from one of the additional operations. The animal was restrained in a cloth sack, its head protruding through an opening. Leads with plugs established the link between the chronic electrodes and the preamplifier of a Neurolog modular system. The potentials were bandpass-filtered between 10 and $100 \mathrm{~Hz}$ and monitored with a storage oscilloscope. 3 to 5 superposed individual potentials were photographed from the oscilloscope screen. An averager module derived the mean responses evoked by 32 stimulus presentations. These averaged responses were written out with a penrecorder or photographed from an oscilloscope display. All the latencies mentioned in the text are measured to the first inflection from the baseline.

Auditory stimuli were generated with a variable frequency sinewave oscillator gated by a trapezoid pulse generator set to give a pulse with a rise- and falltime of $1 \mathrm{~ms}$, a duration of $6 \mathrm{~ms}$ and an interstimulus interval of $2.3 \mathrm{~s}$. The amplitude of the tone bursts was set with a variable gain amplifier. The frequency setting of the oscillator was monitored with a universal counter. The subject was placed within a soundproof anechoic chamber $(140 \mathrm{~cm} \times 110 \mathrm{~cm} \times 120 \mathrm{~cm})$ with the loudspeaker $40 \mathrm{~cm}$ in front of it. The sound pressure delivered was measured by placing the microphone of a calibrated sound pressure meter immediately above the pigeon's head and temporarily lengthening the pulse duration to $10 \mathrm{~s}$ without altering the other stimulus parameters.

Vibratory stimuli were generated with two different arrangements. A transducer constructed from a loudspeaker devoid of its membrane and provided with a blunt probe was used for some exploratory measurements. An excursion amplitude of $25 \mu \mathrm{m}$ was set throughout by observing a whisker attached perpendicularly to the vibrator probe against a graticule with a binocular microscope while it was illuminated stroboscopically. For stimulation the trapezoid pulse generator output had a rise/fall time of $25 \mathrm{~ms}$ and a duration of $50 \mathrm{~ms}$. The effective range of the vibrator extended to maximally $1.4 \mathrm{kHz}$.

A commercial vibration transducer (Ling) equipped with a proximity transducer (Vibrometrics) that permitted direct monitoring of the excursion amplitudes of the stimulation stylus was used for more critical experiments. This system allowed vibration frequencies from 0.15 to $5 \mathrm{kHz}$. A stimulus envelope of triangular shape was produced by setting both the rise and the immediately following fall of the trapezoid pulse generator to $5 \mathrm{~ms}$. As the vibrator produced a faintly audible sound at the higher frequencies, the ears of the subjects were blocked with small cotton plugs dipped in a lanoline based paste. This measure could be shown to effectively prevent any evoked responses to the air conducted sound. The probe was positioned against the tip of the subject's beak with the help of a heavy stand while the pigeon's head was held firmly clamped by the connectors cemented to its skull. The interstimulus interval continued to be $2.3 \mathrm{~s}$.

The soft palate was stimulated electrically by holding the subject's beak closed over a pair of parallel, closely spaced, thin stainless steel bars connected to a stimulus isolation unit delivering $1 \mathrm{~ms}$ square pulses of $50 \mu \mathrm{A}$ at $2.3 \mathrm{~s}$ intervals.

Vestibular stimuli were delivered by connecting a stimulus isolation unit to the relevant head mounted connector and delivering $1 \mathrm{~ms}$ square pulses of $40 \mu \mathrm{A}$ amplitude at the same intervals $(2.3 \mathrm{~s})$. Natural rotational stimulation of the head was obtained by clamping the head-mounted connector of the subjects to the axle of a pendulum. The body rested immobile on a platform. Head rotations in both directions around all three axes were performed. Repeated head rotations were achieved by releasing the pendulum, previously armed by hand, from a silent electromagnetic catch activated by $50 \mathrm{~ms}$ offpulses at $5 \mathrm{~s}$ intervals. The angular extent of the swings was approximately $45^{\circ}$ and the initial angular acceleration was $26 \cdot 10^{3} \mathrm{deg} / \mathrm{s}^{2}$.

After the experiments had been completed the animals were anaesthetized and perfused transcardially, first with saline and then with formalin. After the electrodes had been withdrawn the brains were removed from the skull and embedded in eggyolk. After hardening with formalin vapour the brains were sectioned at $40 \mu \mathrm{m}$ with a freezing microtome and stained with cresyl violet.

\section{Results}

The brain sections were examined with a microscope and the electrode tip locations were transferred onto drawings based on the Karten and Hodos (1967) pigeon brain atlas. Figure 1 shows typical placements in the three relevant structures.

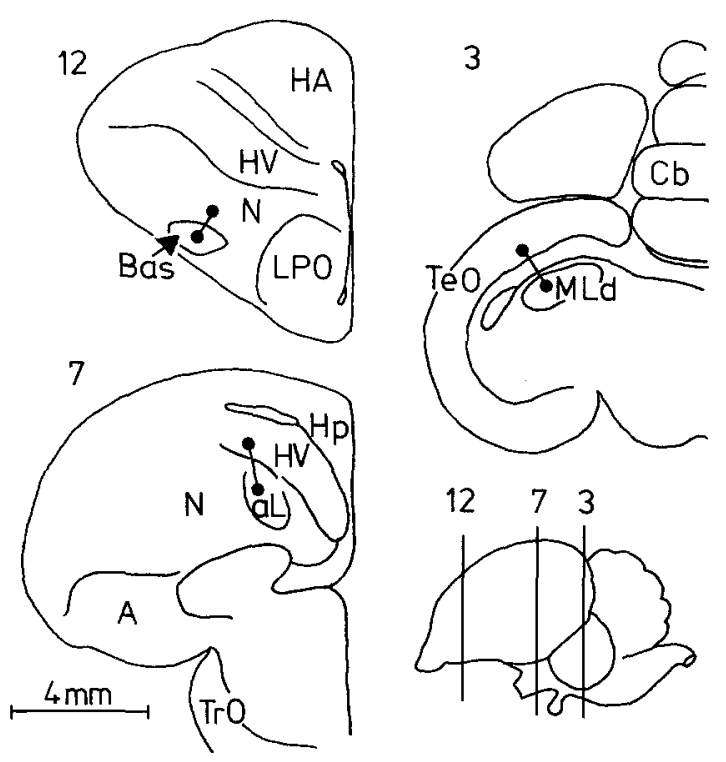

Fig. 1. Examples of electrode positions in the nucleus basalis prosencephali (Bas), the area $\mathrm{L}(a L)$ and the nucleus mesencephalicus lateralis, pars dorsalis $(M L d)$ reconstructed from lesion marked histological sections. Drawings of brain sections based on the Karten and Hodos (1967) atlas. Further abbreviations: archistriatum $(A)$, cerebellum $(C b)$, hyperstriatum accessorium $(H A)$, hippocampus $(H p)$, hyperstriatum ventrale $(H V)$, lobus parolfactorius (LPO), neostriatum $(N)$, tractus opticus $(\operatorname{Tr} O)$ 


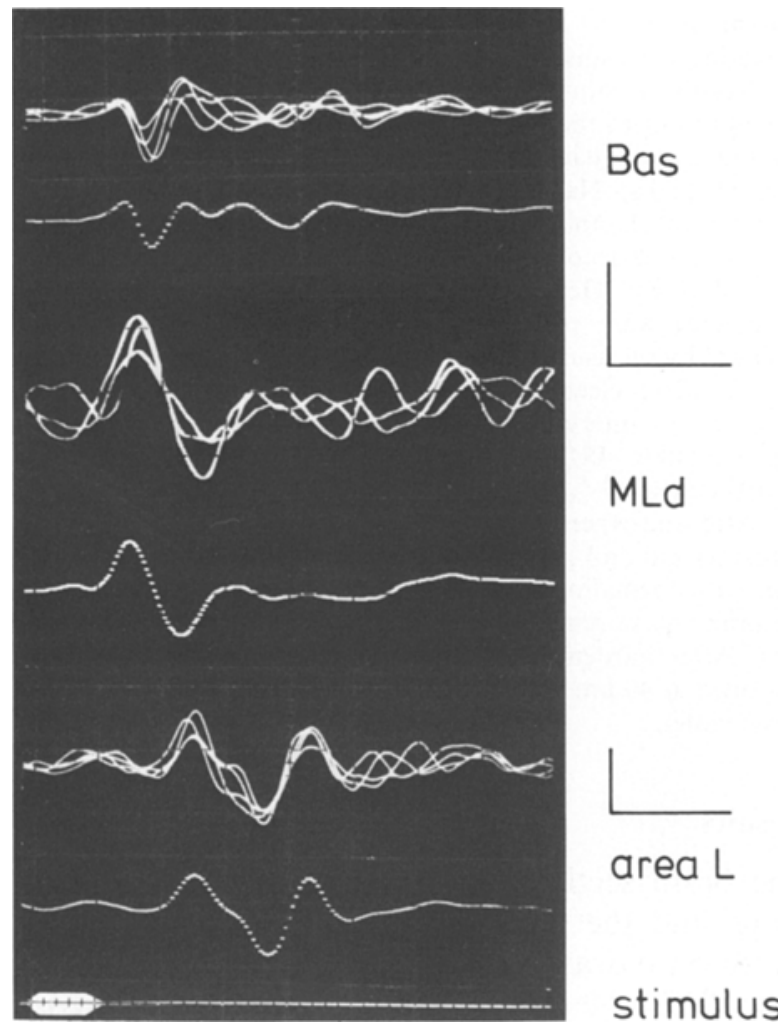

Fig. 2. Superposed and averaged auditory evoked potentials from the nucleus basalis (Bas), the nucleus mesencephalicus lateralis, pars dorsalis $(M L d)$ and the area $\mathrm{L}$ of the pigeon. Calibrations: $20 \mu \mathrm{V}$ and $10 \mathrm{~ms}$. No polarity is indicated as recordings are from bipolar pairs of electrodes. The same applies to all remaining evoked potentials illustrated

\section{Auditory sensitivity}

The auditory stimuli yielded evoked responses in the Bas, the aL and the MLd with a latency to the first inflection of 6-8 ms, 12-14 $\mathrm{ms}$ and 5-6 ms, respectively. This is in accordance with the earlier reports cited in the Introduction. Examples of the evoked potentials are shown in Fig. 2.

To measure the frequency sensitivity of the Bas and the MLd or the area L locations the peak-topeak amplitude in $\mu \mathrm{V}$ of the average evoked response to a stimulus of a $1000 \mathrm{~Hz}$ and $50 \mathrm{~dB}$ (SPL) was taken as standard. This procedure compensated for the appreciable variations in absolute amplitudes of the potentials recorded from the various sites. As the frequency of the stimulus was quasirandomly varied through 15 preselected steps down to $200 \mathrm{~Hz}$ and up to $10 \mathrm{kHz}$ the intensity of the relevant stimulus was adjusted until the amplitude of the evoked potential was within $\pm 5 \%$ of the standard amplitude for two successive averages. The sound pressure in $\mathrm{dB}$ (SPL) required to evoke the standard response was noted for each

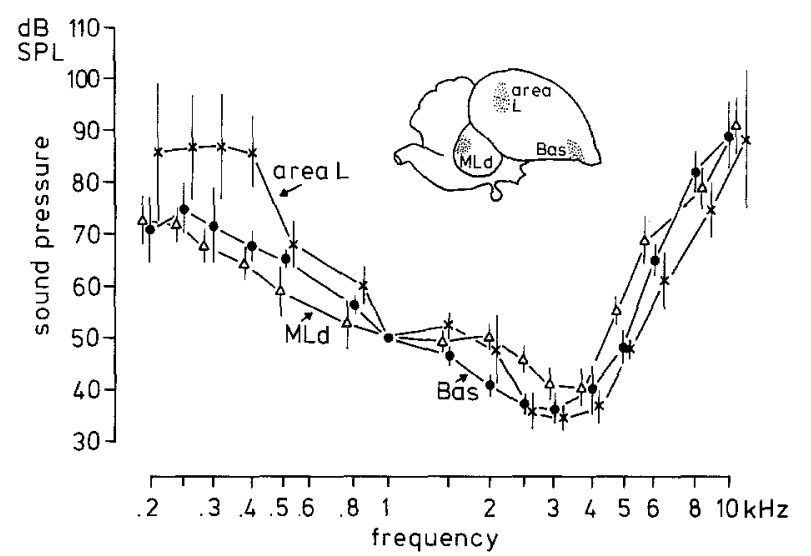

Fig. 3. Audiograms based on evoked potentials from the Bas, $M L d$ and the area $L$ of the pigeon. Bas: average of the mean audiograms of three pigeons. MLd and area L: means of 5 measurements, each from one recording site. $5 \%$ confidence limits are indicated. All averages are referted to the response to $1000 \mathrm{~Hz}$ as standard

frequency step. For each frequency step the procedure was repeated 5 times for each recording site. The averages together with the $5 \%$ confidence limits of these repeated measures are shown for the MLd and area L sites in Fig. 3. Means of these audiograms over the 3 subjects are plotted for the Bas sites with their $5 \%$ confidence limits and also shown in Fig. 3.

To construct more complete audiograms for the Bas sites, the intensity of the stimulus tone at a given frequency was varied in a separate series of measurements in set steps of $10 \mathrm{~dB}$ from 40 to $90 \mathrm{~dB}$ (SPL). The average evoked potentials (32 sweeps) were recorded for each of these stimulus intensities. The peak-to-peak amplitude of the evoked potentials corresponding to each intensity step was measured from the graticule of the oscilloscope display and plotted against the intensity. This was repeated for tone stimuli of 500, 1000 , 2000,4000 and $8000 \mathrm{~Hz}$. Between each measurement there was an interval of between 1 to $2 \mathrm{~min}$. 3 such series of measurements were obtained for each of the 3 recording sites. Linear regressions between sound pressures and evoked potential amplitudes were calculated for each frequency and each recording site on the basis of this data. The regression lines for all 3 Bas sites were quite similar. Mean regression lines were therefore computed over the three Bas sites, samples of which are shown in Fig. 4.

Using the slopes of these mean regression lines, equal evoked response profiles were calculated, taking the mean frequency sensitivity curve of the Bas shown in Fig. 3 as the origin. Profiles chosen 


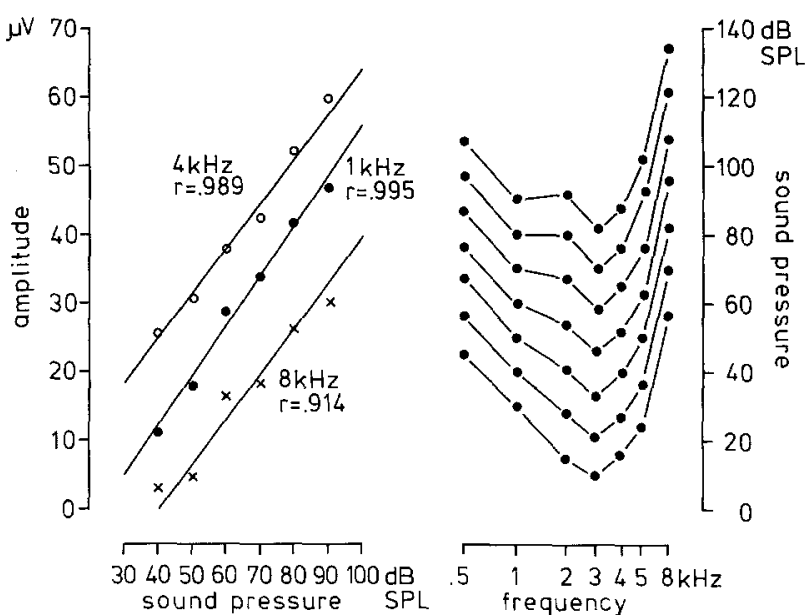

Fig. 4. Samples of sound intensity/response amplitude regressions for the Bas. Equal response audiograms derived from such regression lines in conjunction with the Bas audiogram of Fig. 3 (see text for further explanations)

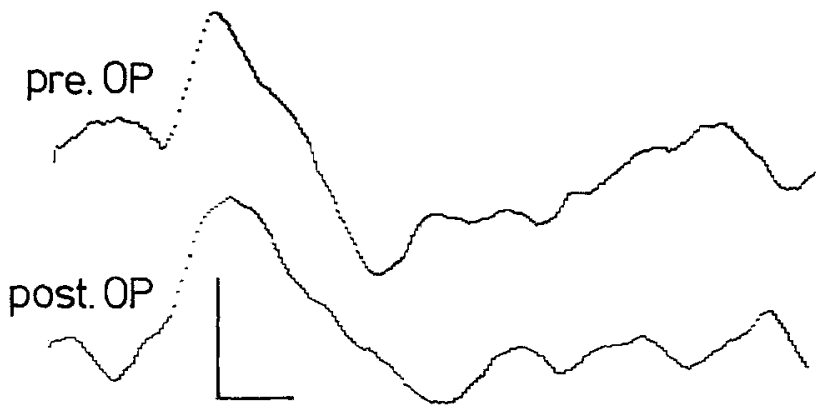

stimulus

Fig. 5. Vibration averaged evoked responses from the Bas of a pigeon before and after bilateral trigeminal transection. Calibrations: $20 \mu \mathrm{V}$ and $5 \mathrm{~ms}$

to be $10 \mathrm{~dB}$ apart at the reference frequency of $1000 \mathrm{~Hz}$ are illustrated in Fig. 4.

\section{Vibratory sensitivity}

The vibratory stimuli yielded evoked potentials in the Bas that had a latency of $3-4 \mathrm{~ms}$ to the first inflection (Fig. 5). The sensitivity to such stimuli was studied in two phases. During the first exploratory phase the amplitude of the evoked potentials to a standard $25 \mu \mathrm{m}$ amplitude stimulus was measured at 8 predetermined frequency steps between 150 and $1400 \mathrm{~Hz}$ using the modified loudspeaker vibrator. For each recording site at each frequency step the peak-to-peak amplitude of the average evoked response was measured 3 times. This proce-

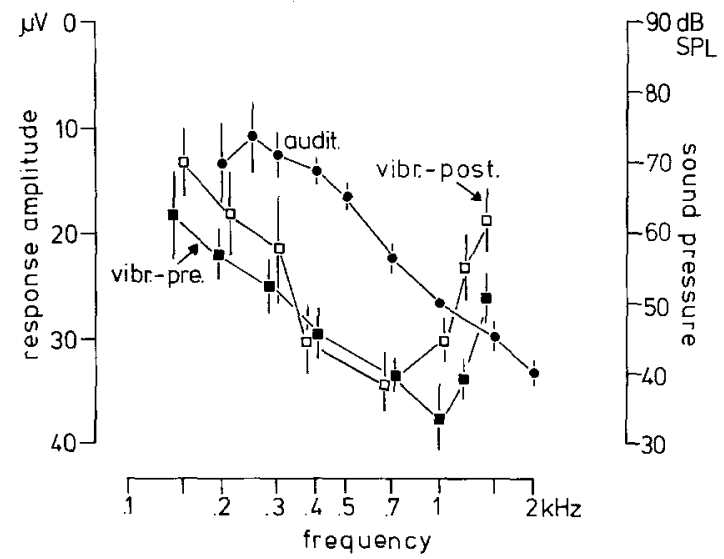

Fig. 6. Vibrograms based on evoked potentials of the Bas of the pigeon. Average before and after cochlear extirpation. Part of the Bas audiogram from Fig. 3 is shown for comparison. $5 \%$ confidence limits are indicated

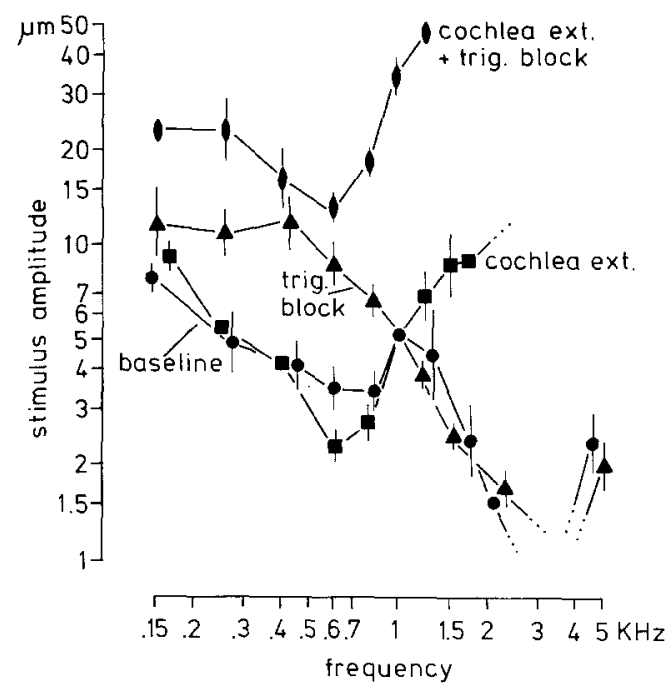

Fig. 7. Vibrograms based on Bas evoked responses of two pigeons. Means with ranges. Circles: before any intervention; triangles: during anaesthetic blockade of trigeminal nerve branches; squares: after extirpation of the cochleae; ovals: after cochlear extirpation and during trigeminal blockade

dure was repeated after removal of the cochleae with the intention of excluding the contribution of potentials due to hearing of bone-conducted (and also of any airborne) sound. Means were calculated for the three subjects and averages of these means over the subjects are plotted in Fig. 6 together with part of the Bas audiogram from Fig. 3 for comparison. A slight loss of high and low frequency sensitivity after bilateral cochlear extirpation is not statistically significant.

The shape of the evoked potentials to square pulse vibration was only slightly modified after cochlear ablation. However, we cannot be sure that this was not due to variations in the mechanical 


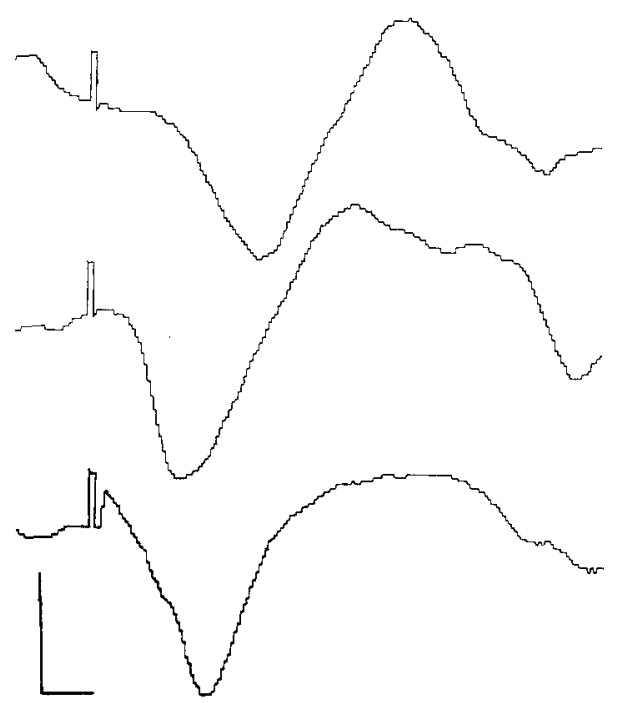

a
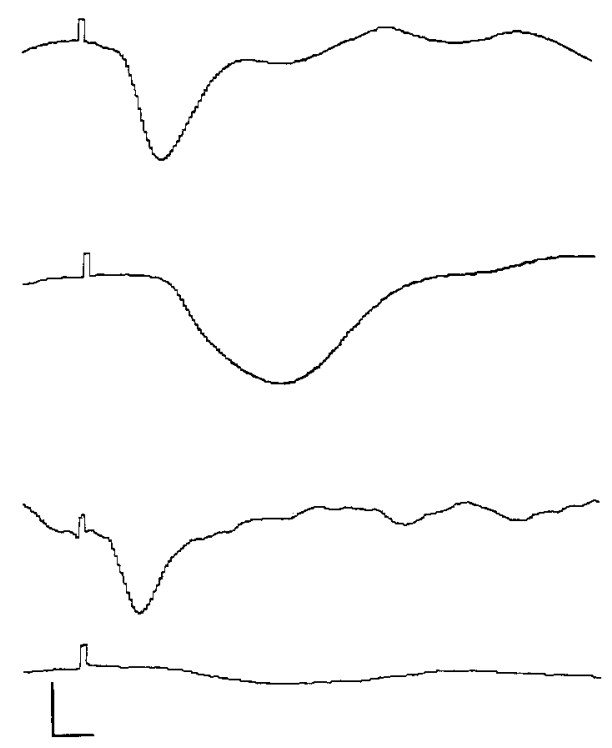

b

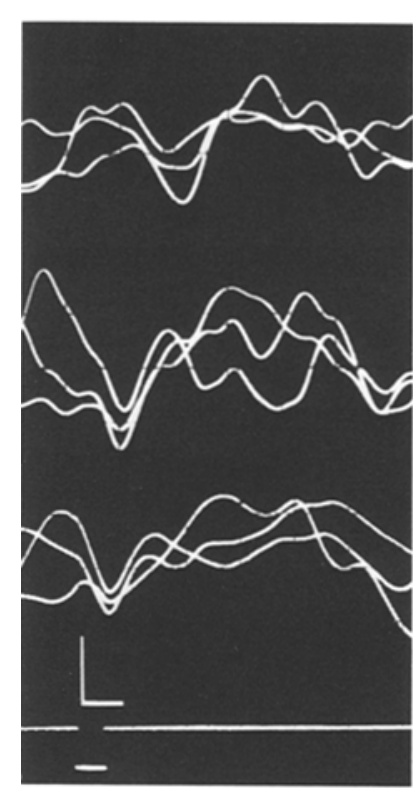

Bas:

audit

vestib.

pre. OP

vestib.

post.OF

stimulu

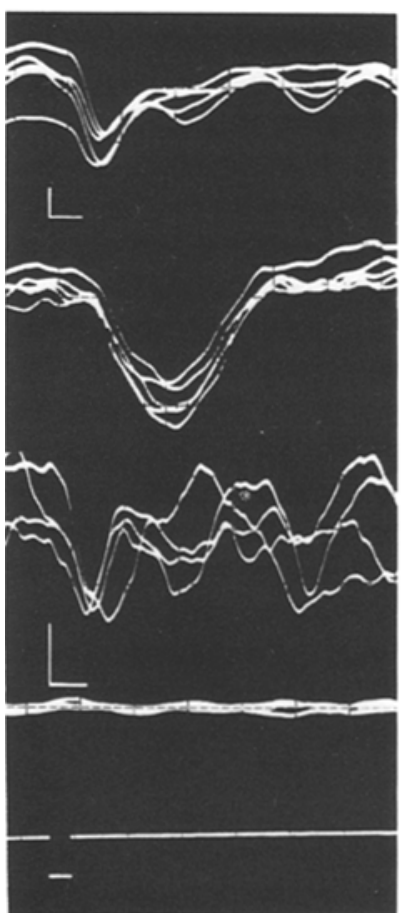

Bas

audit.

area L

audit.

Bas

vestib.

Fig. 8a, b. Averaged and superposed evoked responses of the Bas and area $L$ of the pigeon to auditory and vestibular stimulation. a The vestibular response of the Bas is not affected by cochlear ablation. b The area $\mathrm{L}$ yields no response upon vestibular stimulation.

Calibrations: $20 \mu \mathrm{V}, 10 \mathrm{~ms}$ coupling between the vibrator probe and the beak during successive recording sessions. The success of the extirpation could incidentally be confirmed by the complete absence of auditory evoked potentials both at the Bas and the other recording sites (area L, MLd) after the operation.

Local anaesthesia of the beak, which blocked Bas potentials evoked by electrical stimulation of the palate, slightly modified but certainly did not annul responses to vibration stimuli applied to the beak tip. The bilateral section of the trigeminal nerve branches similarly did not seem to eliminate the potentials evoked by a square pulse vibration (Fig. 5).

In a second phase the vibratory sensitivity of the Bas was determined over a wider range of frequencies (12 steps between $150 \mathrm{~Hz}$ and $5 \mathrm{kHz}$ ) using a special purpose vibration transducer. The vi- 
brogram of two pigeons with chronically implanted Bas electrodes was measured. At each frequency the stimulus amplitude required to elicit the same potential amplitude as obtained with a $1 \mathrm{kHz}$ and $5 \mu \mathrm{m}$ stimulus was determined. The measurements were repeated after the trigeminal nerve branches or ganglion were blocked with local anaesthesia with the intention of isolating the sensitivity due to bone-mediated hearing. After the subjects had recovered from the trigeminus blockade the cochleae were removed and after 3 days of recovery the measurements were repeated. This was designed to isolate the mechanoreceptive sensitivity. Finally the vibrogram was determined again in the cochlea-ablated pigeons after trigeminal blockade to determine any remaining sensitivity. The vibrograms obtained under all these 4 conditions are illustrated in Fig. 7.

It is apparent that the baseline vibrogram has two high sensitivity regions, one at about $0.6-0.7 \mathrm{kHz}$ and another between 3 and $4 \mathrm{kHz}$. The trigeminal blockade strongly attenuated the low frequency sensitivity but did not completely eliminate it. It must be remembered that the normal auditory sensitivity of birds, differently from mammals, extends far into the lower frequencies (Kreithen and Quine 1979; Klinke and Schermuly 1986). Cochlear extirpation on the other hand leaves the low frequency sensitivity unmodified but attenuated drastically that at higher frequencies which is thus shown to be due to hearing of boneconducted sound. Finally the additional trigeminal block considerably elevates the thresholds of the remaining sensitivity so much so that the standard stimulus of $5 \mu \mathrm{m}$ amplitude at $1 \mathrm{kHz}$ no longer evokes a response. To achieve comparability the stimulus amplitude was increased until the potentials at $1 \mathrm{kHz}$ had again the size of the earlier responses to the standard stimulus.

\section{Vestibular stimulation}

The vestibular system was stimulated via the electrodes implanted into the contralateral sagittal semicircular canal. Evoked responses from the Bas had a latency of 3-4 ms, appreciably shorter than the auditory evoked potentials at the same site (6-8 ms). The removal of the cochlea on the stimulated side had no appreciable effect on the potentials evoked by vestibular stimulation (Fig. 8a).

The responses were thus of truly vestibular origin and not auditory potentials due to an unintentional spreading of the electrical stimulus to the cochlea. Similarly, while auditory stimulation elicited evoked potentials both in Bas and aL, vesti- bular stimulation only produced an evoked response of any amplitude in the Bas (Fig. $8 \mathrm{~b}$ ). If the latter evoked potentials were of cochlear origin they should also have yielded responses in area L. It remains uncertain of course whether the evoked responses are due to the stimulation of the sagittal canal ampulla only or whether the stimulus also spreads to the other receptor pads of the vestibular organ.

Forward head rotations around the transversal axis yielded clear cut evoked potentials with latencies of 5-6 ms. Other rotation axes and directions probably yielded lesser responses but this was not examined systematically during the experiments reported here.

\section{Discussion}

This series of experiments has again confirmed that the Bas of the pigeon receives short latency auditory input of true cochlear origin (Naumov and Iljitschew 1964; Delius et al. 1979) and dismisses the notion that the Bas auditory responses are artefacts due to unintended mechanostimulation of trigeminal sensory structures (Karten 1968; Witkovsky et al. 1973). Furthermore it has now been shown that the audiogram of the Bas, as assessed by its evoked responses, is quite similar to that of two stations of the orthodox auditory projection of birds, the MLd (homologous to the inferior colliculus of mammals) and the aL (homologous to the auditory cortex of mammals). Slight deviations of the a $\mathrm{L}$ audiogram in the low frequency region could easily be due to the fact that the aL is tonotopically organized over a considerable volume of tissue (Bonke et al. 1979) and our electrode might have preferentially picked up the activity of the higher frequency projection region. Overall the audiograms are also similar in shape to those obtained with various behavioural techniques in the pigeon by several authors and recently illustrated by Goerdel-Leich and Schwartzkopff (1984).

All the audiograms evince a relatively high sensitivity at low frequencies and a steep loss of sensitivity at high frequencies. That is characteristic for the audiogram of this species as compared, for example, with the human audiogram. We could not find evidence that the Bas of the pigeon is specialized for the processing of higher frequencies as has been suggested for the Bas of starlings on the basis of single unit recordings (M. Kirsch, pers. comm.) and as one might perhaps have expected if it was especially tuned to feeding-related sounds.

The vibratory sensitivity of the Bas upon mechanical stimulation of the beak has a tuning curve 
with one minimum centred around a best frequency of about $700 \mathrm{~Hz}$ and another located at about $3 \mathrm{kHz}$. The sensitivity components which give rise to these two minima could be largely isolated from one another by trigeminal blockade and cochlear extirpation. The first component is similar to that characterizing the vibrogram of the wing and the leg measured in the pigeon, either behaviourally with a heart rate conditioning technique or electrophysiologically from single Herbst corpuscles (Shen 1983; Hörster et al. 1983). Compared with the vibratory sensitivity of mammals the relatively high frequency responsiveness is striking. The dermal palate of the pigeon is known to contain both Herbst and Merkel corpuscles in considerable numbers that certainly could mediate this mechanosensitivity (Necker 1983; see also Necker 1985). But it remains possible that the vibrational input that we employed also reached the Bas through mechanoreceptors located elsewhere in the jaw system. These perhaps are supplied by other trigeminal branches, or even other cranial nerves as some low frequency responsivity remained even after section or blockade of the trigeminal branches innervating the beak and following cochlear ablation.

That bone/cochlea-mediated hearing was responsible for the higher frequency optimum was clearly established by the cochlear extirpations. They essentially eliminated the vibratory sensitivity above $1.5 \mathrm{kHz}$. It is important to stress that the procedures used ensured that this effect on the vibrogram was not due somehow to a loss of airborne sound sensitivity but truly due to the loss of bone-conducted sound sensitivity.

The continued presence of Bas responses to wide band square pulse vibrations after section or blockade of the ophthalmic, maxillary and mandibular trigeminal nerve branches is explained by this contribution of bone-mediated hearing. Such a contribution is in fact to be expected as the jaw bones of pigeons, and of birds in general, are mechanically closely coupled with the otic capsule. In fact the tympanum itself is in part suspended from a bone, the quadratum, that is an integral part of the jaw-bone system (Delius 1985). Incidentally, we also observed that vibratory stimuli evoked responses in area $\mathrm{L}$ but by themselves they cannot be construed as representing bone-hearing potentials since a somatosensory projection receiving afferents from the head is known to exist in the immediate neighbourhood of the auditory projection (Delius and Bennetto 1972).

A further result of this study is that it confirmed physiologically a hypothesis that derived from anatomical evidence. Schall et al. (1986) found that the nucleus vestibularis superior (VS) of the medulla projects directly to the Bas. Here we showed that, indeed, electrical stimulation of the vestibular organ elicits evoked potentials with a latency consistent with a direct, oligosynaptic pathway even when possible artefactual cochlear stimulation is excluded. More natural stimulation of the vestibular system by head rotation is equally effective in producing responses. Incidentally, the possibility that the potentials could be due to nystagmic eye movement artefacts can be rejected. Firstly, the brief electrical stimulation used did not elicit any observable ocular responses. Secondly, recent experiments employing head rotations as stimuli showed that the corresponding evoked responses of the Bas are not suppressed by ocular succinyle/atropine applications that abolish all oculomotor activity. The combined anatomical and physiological evidence is reasonable proof that yet another rhomb-mesencephalic sensory nucleus, the VS, in addition to the nucleus sensorius principalis nervi trigemini ( $\mathrm{PrV}$ ) and the nucleus lemniscus lateralis, pars ventralis (LLv), monosynaptically accesses the Bas, bypassing the classical thalamic stations of the more orthodox sensory pathways to the telencephalon.

As stated at the beginning of this report there is ample evidence that the Bas is functionally involved in the control of pecking movements. It remains now to briefly consider how the present findings fit in with this role of the Bas. An exquisite vibratory sensitivity seems essential for a neural structure that controls a motor act that involves impact with the substrate. Elsewhere we have pointed out that the impact also generates sound and adduced behavioural evidence that to control its pecking the pigeon uses at least as feedforward information the airborne component (Delius 1985). There is now a strong possibility that boneconducted sound is similarly utilized. The auditory responsiveness of the Bas provides a basis for the reafferent of peck generated sound carried by either medium. Finally the pecking act involves considerable head accelerations that can, if uncontrolled, produce injury. Fast vestibular feedback or feedforward seems ideally suited to ensure an adequate course of movement, particularly if one takes into account that in the critical final phase of pecks, pigeons are effectively blind as they then always close their eyes to protect them from substrate backscatter (Delius 1985).

Acknowledgements. This research was supported by the Deutsche Forschungsgemeinschaft through its Sonderfor- 
schungsbereich 114 and by the Wissenschaftsminister of Nordrhein Westfalen. We thank Julia Delius, Dr. Jacky Emmerton, Dagmar Hagenkötter and Günter Keim for assistance of various kinds.

\section{References}

Berkhoudt H, Dubbeldam JL, Zeilstra S (1981) Studies on the somatotopy of the trigeminal system in the mallard, Anas platyrhynchos L. IV. Tactile representation in the nucleus basalis. J Comp Neurol 196:407-420

Berkhoudt H, Klein BG, Zeigler HP (1982) Afferents to the trigeminal and fascial motor nuclei in pigeon (Columba livia): Central connections of jaw motorneurons. J Comp Neurol 209:301-312

Bonke D, Scheich H, Langner G (1979) Responsiveness of units in the auditory neostriatum of the Guinea fowl (Numida meleagris) to species-specific calls and synthetic stimuli. I. Tonotopy and functional zones of field L. J Comp Physiol $132: 243-255$

Boord RL (1968) Ascending projections of the primary cochlear nuclei and nucleus laminaris in the pigeon. $J$ Comp Neurol $133: 523-542$

Correia MJ, Eden AR, Westlund KN, Coulter JD (1982) Organization of ascending auditory pathways in the pigeon (Columba livia) as determined by autoradiographic methods. Brain Res 234:205-212

Delius JD (1971) Foraging behavior patterns of herring gulls elicited by electrical forebrain stimulation. Experientia 27:1287-1289

Delius JD (1985) The pecking of the pigeon: free for all. In: Lowe CF, Richelle M, Blackman DE, Bradshaw CM (eds) Behaviour analysis and contemporary psychology. Erlbaum, Hillsdale, pp 53-81

Delius JD, Bennetto K (1972) Cutaneous sensory projections to the avian forebrain. Brain Res 37:205-221

Delius JD, Runge TE, Oeckinghaus H (1979) Short latency auditory projections to the frontal telencephalon of the pigeon. Exp Neurol 63:594-609

Dubbeldam JL, Brauch CSM, Don A (1981) Studies on the somatotopy of the trigeminal system in the mallard, Anas platyrhynchos L. III Afferents and organization of the nucleus basalis. J Comp Neurol 196:391-405

Goerdel-Leich A, Schwartzkopff J (1984) The auditory threshold of the pigeon (Columba livia) by heart-rate conditioning. Naturwissenschaften 71:98

Harman AL, Phillips RF (1967) Responses in the avian forebrain evoked by click stimuli. Exp Neurol 18:276-286

Hörster W, Shen J, Schwartzkopff J (1983) Electrophysiological studies on the vibrational sensitivity in the pigeon. Naturwissenschaften $70: 151$

Karten JH (1968) The ascending auditory pathway in the pigeon (Columba livia). I. Diencephalic projections of the inferior colliculus (nucleus mesencephalicus lateralis, pars dorsalis). Brain Res 6:409-427

Karten HJ (1969) The ascending auditory pathway in the pigeon (Columba livia). II Telencephalic projections of the nucleus ovoidalis thalami. Brain Res 11:134-153

Karten HJ, Hodos W (1967) A stereotaxic atlas of the brain of the pigeon. Johns Hopkins Press, Baltimore Maryland

Karten HJ, Hodos W (1970) Telencephalic projections of the nucleus rotundus in the pigeon (Columba livia). J Comp Neurol 140:35-52

Kirsch M (1983) Antworteigenschaften und Verbindungen des akustischen Zentrums mit kurzer Latenz im frontalen Vorderhirn (Sturnus vulgaris L.). Verh Dtsch Zool Ges 76:296

Klinke R, Schermuly L (1986) Inner ear mechanics of the crocodile and avian basilar papillae in comparison to neuronal data. Hearing Res (in press)

Kreithen ML, Quine DB (1979) Infrasound detection by the homing pigeon, Columba livia. J Comp Physiol 129:1-4

Macdar AW, Rausch LJ, Wenzel BM, Hutchinson LV (1980) Electrophysiology of the olfactory pathway in the pigeon. J Comp Physiol 137:39-46

Mallin HD, Delius JD (1983) Inter- and intraocular transfer of colour discriminations with mandibulation as an operant in the head-fixed pigeon. Behav Anal Lett 3:297-309

Naumov NP, Iljitschev WD (1964) Klanganalyse im Großhirn der Vögel. Naturwissenschaften 51:644

Necker R (1983) Somatosensory system. In: Abs M (ed) Physiology and behaviour of the pigeon. Academic Press, London, pp 169-192

Necker R (1985) Receptors in the wing of the pigeon and their possible role in bird flight. In: Nachtigall W (ed) Biona Report 3. Gustav Fischer, Stuttgart, pp 433-444

Parker DM, Delius JD (1972) Visual evoked potentials in the forebrain of the pigeon. Exp Brain Res 14:198-209

Rieke GK, Wenzel BM (1978) Forebrain projections of the pigeon olfactory bulb. J Morphol 158:41-55

Ritchie TLC, Cohen DH (1977) The avian tectofugal visual pathway: projections of its telencephalic target, the ectostriatal complex. Neurosci Abstr 3:275

Schall U, Güntürkün O, Delius JD (1986) Sensory projections to the nucleus basalis prosencephali of the pigeon. Cell Tissue Res (in press)

Schwartzkopff J (1949) Über Sitz und Leistung von Gehör und Vibrationssinn bei Vögeln. Z Vergl Physiol 31:527-608

Shen J (1983) A behavioral study of vibrational sensitivity in the pigeon (Columba livia). J Comp Physiol 152:251-255

Wallenberg A (1903) Der Ursprung des Tractus isthmo-striatus (oder bulbo-striatus) der Taube. Neurol Zentralbl 22:98-101

Wallenberg A (1966) Beiträge zur vergleichenden Anatomie des Zentralnervensystems. J Hirnforsch 7:275-300

Wild JM, Zeigler HA (1980) Central representation of the jaw muscles within the facial and trigeminal nuclei of the pigeon (Columba livia). J Comp Neurol 192:175-201

Wild JM, Arends JJ, Zeigler HP (1984) A trigeminal sensorimotor circuit for pecking, grasping and feeding in the pigeon (Columba livia). Brain Res 300:146-151

Wilson VJ, Felpel LP (1972) Specificity of semicircular input to neurons in the pigeon's vestibular nuclei. J Neurophysiol 35:253-264

Witkovsky P, Silver R, Zeigler HP (1973) The nucleus basalis of the pigeon: a single unit analysis. J Comp Neurol 147:119-128

Wold JE (1975) The vestibular nuclei in the domestic hen ( $\mathrm{Gal}$ lus domesticus). II. Primary afferents. Brain Res 95:531-543

Zecha A (1962) The pyramidal tract and other telencephalic efferents in birds. Acta Morphol Neerl Scand 5:194-195

Zeier H, Karten HJ (1971) The archistriatum of the pigeon: organization of afferent and efferent connections. Brain Res $31: 313-326$

Zeigler HP, Miller M, Levine RR (1975) Trigeminal nerve and eating in the pigeon (Columba livia), neurosensory control of the consummatory responses. J Comp Physiol Psychol $89: 845-858$

Zeigler HP (1976) Feeding behavior of the pigeon. Adv Study Behav 7:285-389 